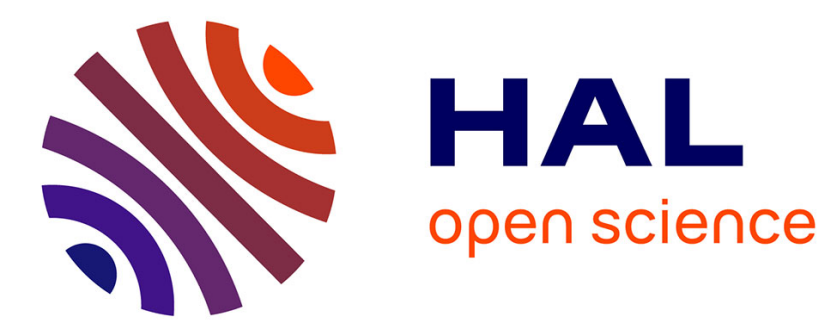

\title{
EZID: A new approach to hazard identification during the design process by analysing energy transfers
}

Nicholas de Galvez, Jacques Marsot, Patrick Martin, Ali Siadat, Alain Etienne

\section{To cite this version:}

Nicholas de Galvez, Jacques Marsot, Patrick Martin, Ali Siadat, Alain Etienne. EZID: A new approach to hazard identification during the design process by analysing energy transfers. Safety Science, 2017, 95, pp.1-14. 10.1016/j.ssci.2017.02.001 . hal-02309165

\section{HAL Id: hal-02309165 https://hal.science/hal-02309165}

Submitted on 9 Oct 2019

HAL is a multi-disciplinary open access archive for the deposit and dissemination of scientific research documents, whether they are published or not. The documents may come from teaching and research institutions in France or abroad, or from public or private research centers.
L'archive ouverte pluridisciplinaire HAL, est destinée au dépôt et à la diffusion de documents scientifiques de niveau recherche, publiés ou non, émanant des établissements d'enseignement et de recherche français ou étrangers, des laboratoires publics ou privés. 
EZID: A new approach to hazard identification during the design process by analysing energy transfers

\section{de Galvez, N., Marsot, J. , Martin, P. , Siadat, A., Etienne, A}

1. Introduction

In 2014, out of the 621111 work accidents declared in France, about 5\% were related to machines [1]. Regarding these accidents in particular and occupational health and safety in general, design is a source of prevention whose advantages no longer need demonstrating [2]. This approach is called "integrated prevention" and is schematized in figure 1. It is codified by European directive 2006/42/EC, known as the "Machinery directive" [3], and in the associated standards. The prevention strategy recommended in these texts focuses on the a priori evaluation of risks; it gives the machine designer the objective of obtaining the lowest possible risk level according to the state of the art.

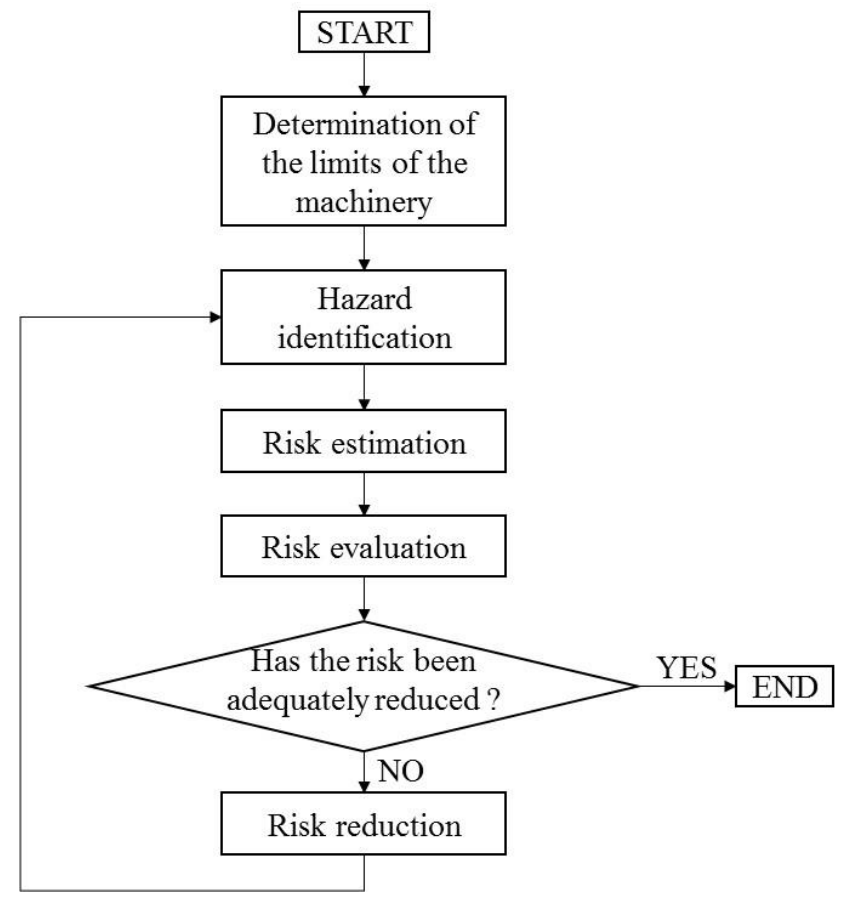

Figure 1. Simplified description of the integrated prevention process

However, except for some items of catalogue machinery for which specific standards exist (known as type "C") and that incorporate this risk assessment, the designers of special machines and the integrators of specific equipment in production lines are limited to relying on transversal standards (types "A" and "B"), especially standard NF EN ISO 12100 [4] relating to general design principles.

It is also important to recall that in France "special machinery" (i.e. machine designed specifically to answer the needs of a client) is mostly designed and manufactured by small or medium sized enterprises [5]. The designers belonging to these SMEs (project managers, engineers and technicians of engineering offices) are not specialised in "prevention" and have no formal resources or tools adapted for performing a priori risk assessments. Therefore, on the one hand they are limited to the risk families closest to their field of experience (for example, mechanical), while on the other hand, they carry out this assessment more often at the end of the project, once all the technical solutions have been defined. Furthermore, the data required for risk assessments (severity of harm, frequency and/or exposure, probability of occurrence, possibility of avoidance) are not directly linked to the design data, thereby widening the gap between design and safety. Occupational health and safety requirements are thus treated as constraints of adaptation and correction rather than as design requirements [6].

To solve this issue, a method called EZID (Energy analysis for systematic haZard Identification during Design) is proposed in this article to assist the designers of special manufacturing machinery to identify hazards in order to help them perform risk analysis early in the design process. This approach is intended to define the link between design parameters with those used in risk assessment methods: severity of harm and probability of its occurrence [4]. 
To be considered efficient, this method must have the following four characteristics. It must be:

- generic to allow its use independently of the different types of risk, the different design approaches followed and the sectors of activity of the enterprises concerned;

- inductive, by being based on design parameters (causes) to ascertain hazards (effects);

- dynamic and traceable, in order to observe and analyse the evolution of the system's characteristics and the configuration of its components during the different design stages;

- integrated and/or compatible with current design tools and methods to ensure interoperability. It must also be monitored and instrumented with indicators of potential risks in order to quantify and use the data.

The first section provides a literature review of the design and integrated prevention processes. The hypothesis underlying EZID is then presented, followed by the presentation of the model used to ensure its practical implementation. Next, a theoretical presentation of the different steps and elements of EZID is given followed by its application to a real industrial case and the results obtained. The article concludes with a discussion on the current status of EZID and its perspectives.

\section{Literature review}

\subsection{On the design process}

The multiplicity of domains (industrial machines, tools, consumer products, building etc.) and objectives (cost, schedule, quality, performance, safety, etc.), has led to the development of many design methods. However, they share several similarities [7]: they all proceed by dividing the design process into phases. They use similar methods and design tools that generate intermediate design objects. These objects allow the designer to represent the system from the earliest stages of the design process and they serve as milestones for design activities and guarantee the maturity of design parameters [7-9]. Their processing allows making decisions regarding the following phases in the development of a product. X. Godot [8] also established that the activity within each design phase could be summarised by the five following generic tasks: creation, dimensioning, representation, optimisation /evaluation and validation

Therefore, proposing an approach that can be used by all machine designers requires that the intermediary objects [7] and design parameters are based on generic design tasks (cf. Fig. 2).

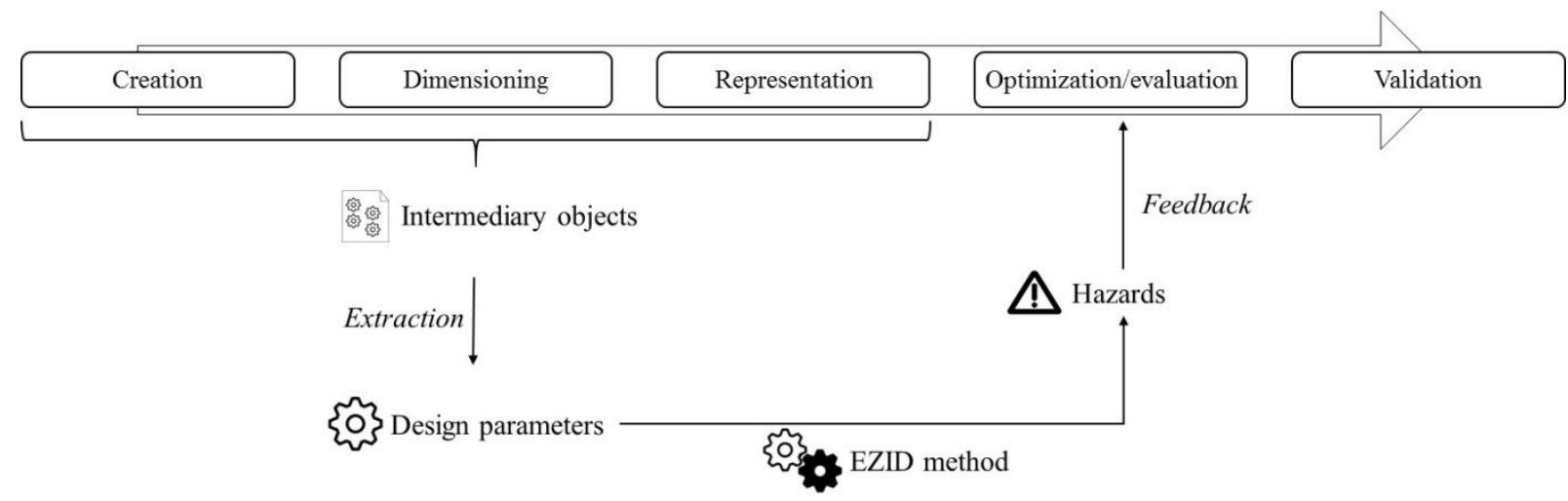

Figure 2. The position of EZID approach in the generic tasks of the design process

\subsection{On integrated prevention}

There is a wide range of works related to integrated prevention in the literature. Among them, it is possible to find studies about risk assessment during the design of nuclear plants [10], comparison between integrated prevention and add-on safety in offshore platforms [11] or proposition of inherently safer design concept for process plants development [12]. Research works dealing with the integration of risk prevention in machinery design mainly focus on three areas: its links with the design process, risk assessment and risk reduction. All these works present limits regarding the objective of helping designers identify hazards.

Based on a state of the art realized by Sadeghi et al. [13], works related to links with the design process mostly propose methods, tools and technics which rely on participatory project reviews [6, 14-15]. In this case hazard identification is based on cooperation between the different actors during these project reviews. For example, the 
work of Jouffroy et al. [17] presented the application of the distributed design theory for safety design to a machine tool in the context of concurrent engineering. Several actors with several points of views (functional, manufacturing, structural, user, human and safety) were involved in the experiment and they communicated using written messages (around 150 were exchanged in order to follow the entire design process). The final solution was directly based on the competencies of the actors who used natural language. No structured language or formal process was applied in this machine tool design process.

Therefore this type of approach does not guide the designer in decision-making when they work autonomously [18]. Furthermore, as these project reviews needs numerical mock-ups or physical prototypes, hazard identification can only be initiated belatedly [11].

Studies on the risk reduction process mostly propose methods or tools that manage [19], analyse [20] or assess [21] preventive measures. These articles help designers to compare and choose the safety measures to be integrated in their design. However, since they are linked to the risk reduction process that occurs after the risk evaluation, they are not related to hazard identification.

Works on risk assessment are mainly focused on estimation and evaluation steps, i.e. the determination of an index used to classify potential risks. The methods proposed differ by the number of parameters used to define severity and exposure, the number of levels used to evaluate these parameters, and how they are combined: matrix, graph, numerical equation, abacus, and chart [22]. Moreover, these methods are mainly specific to one type of hazard, for example mechanical [23] or ergonomic [24]. Consequently, they do not provide an answer to the issue presented here, which concerns the first step of the risk assessment process, i.e. the identification of all types of hazard.

Analysis of the literature leads to the identification of 4 approaches which, a priori, provide an answer to our problem and satisfy the criteria expected (generic, inductive, dynamic and integrated):

- The Factor of Risk (FRis) proposed by Coulibaly et al. [25] indicates whether a risk is present or not in a machine. This factor combines three Boolean parameters: Ph represents the existence of a hazard, Zo the existence of a hazardous area, and HIn the intervention of a worker in the hazardous area. However, this paper does not give solutions for the identification of these parameters, in particular $\mathrm{Ph}$, i.e. whether or not a hazard exists in the machinery;

- Performance Analysis Agent (PAG) [26] is a multi-agent system that represents a worker and their environment through agents linked to modelling (morphological, biomechanical, kinematic, physiological and psychological) and analysis (human factor, risks, economic and industrial performance) integrated in a numerical mannequin. The input parameters of PAG are directly linked to design, but as this is based on CAD tools and numerical mock-ups, it cannot be used at the beginning of the design process.;

- $\quad$ IRAD (Innovative Risk Assessment Design) [27] is a method for simultaneously developing technical and safety functions. By completing the requirement specifications with safety functions, it allows the designer to take technical and safety aspects into consideration at the same time. Then, the designer uses it throughout the design process to verify that each safety function is treated. This method focuses more on the risk reduction phases and does not give solutions for hazard identification.

- The work situation model MOSTRA [28] (in french: MOdèle de Situation de TRAvail) facilitates the simultaneous consideration of multi-viewpoint data based on the concept of risk. Although it defines every link between the concepts that construct a work situation, this model does not provide direct links between design parameters and risk evaluation parameters. As in the previous approach, MOSTRA does not give solutions for hazard identification.

Consequently, we conclude that none of these works completely answers the problem exposed in section I. However, certain of them agree on the fact that hazardous phenomena are linked to energy [27, 29, 30].

The severity of harm is clearly linked to the severity of injuries or damage to health, and to the extent of harm. These parameters are directly related to the level of energy exchanged during the interactions between the machinery and the operator. Thus it is possible to connect the design parameters characterizing these energies to those used for hazard evaluation, in particular the "severity of harm" parameter (cf. Fig. 3). On the contrary, the probability of occurrence is linked only to the organization within which the machine takes part. 


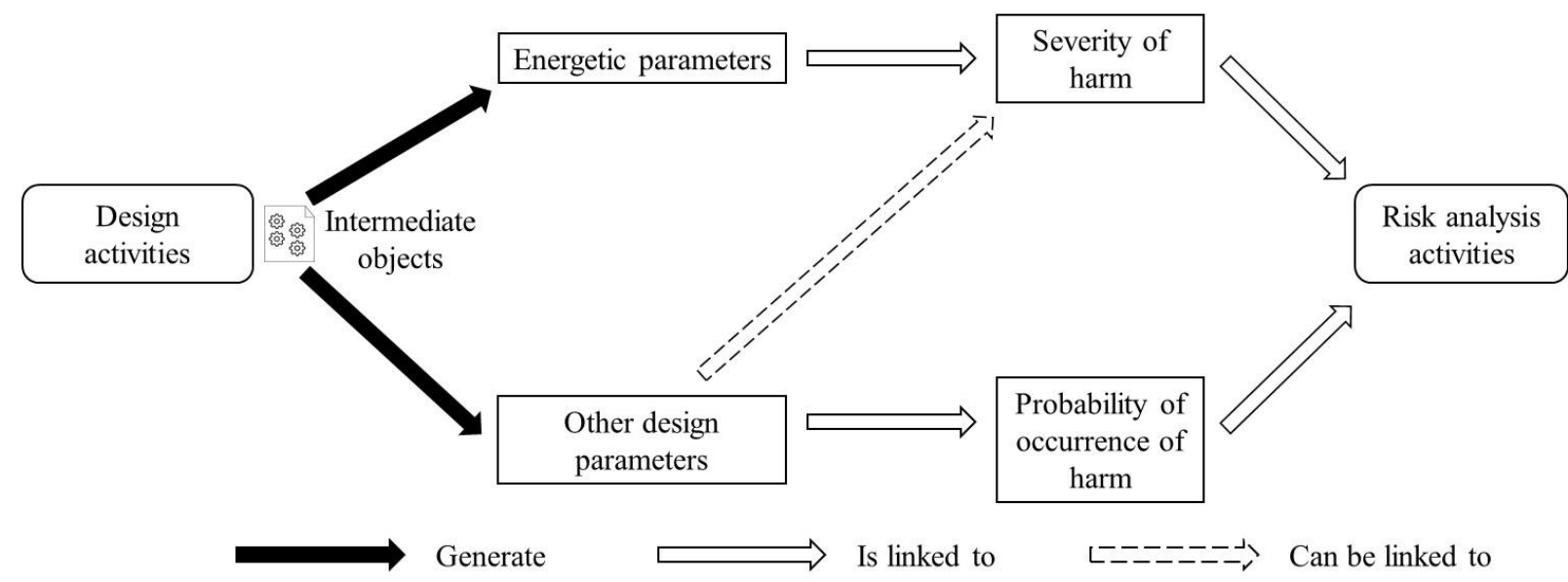

Figure 3. Links between design parameters and those used for risk assessment

Thus hazard identification can be reduced to the identification of energy sources and flows. This can be done throughout the design process since designers progressively characterize these sources and flows during it. The designer can then be informed at the earliest phase of design and thus provide appropriate prevention measures. Once all the energies of the machine have been defined, it is possible to identify all the types of hazard linked to it.

We therefore expanded our bibliographic research to the models used during design for analysing energy sources and flows during product design. Different models can be used for this type of representation [31-35]. We chose to use the Functional-Structural Model (FSMo) [36, 37]. Initially developed to analyse the different kinds of energy flows in an existing complex system, this model has been completed to follow the design process of a mechatronic product from its initial structure. It also takes into account energy dissipations and the worker, and has already been the subject of computerisation. This model is based on four elements (cf. Fig. 4):

- frontiers that delimit a manufacturing system, a subsystem or a component in relation to its external environment;

- functional surfaces that designate the interfaces through which a production system, subsystem or component exchanges energy with its environment. They are crossed by one energy flow and are characterized by energy parameters (effort, current, power, temperature, speed, etc.) and other design parameters (dimensions, shape, type of material, roughness, etc.);

- links that associate two functional surfaces that do not belong to the same component. They therefore characterize the interfaces that can be separated into three types: conductive (C), semi-conductive (SC) or insulating (I);

- internal links that associate two functional surfaces belonging to the same component. They can also be conductive, semi conductive or insulating.
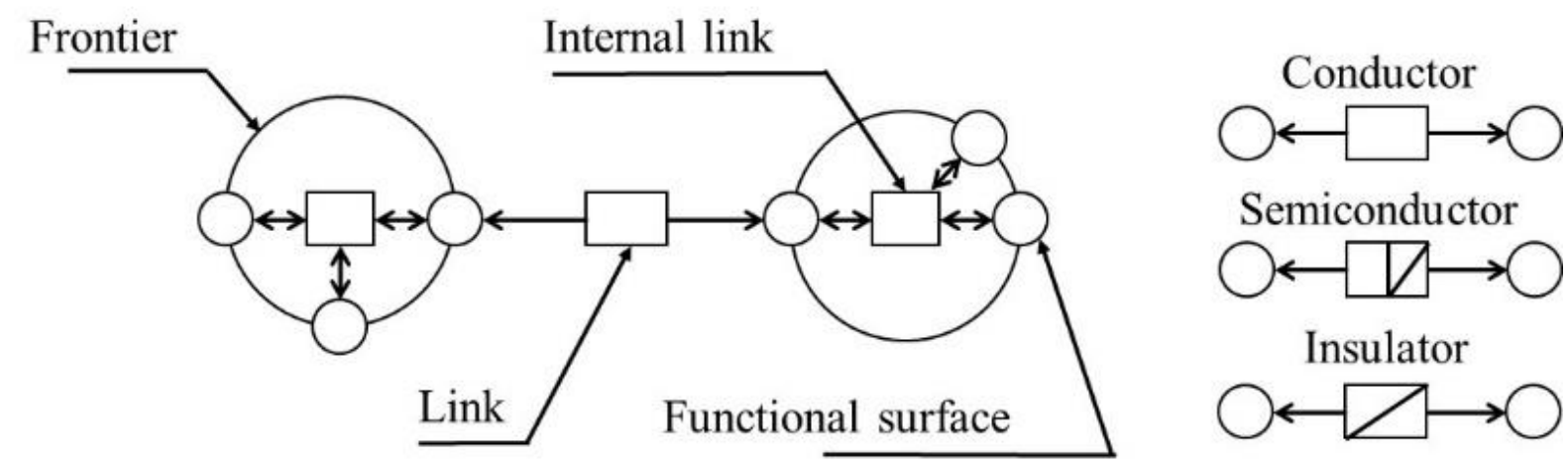

Figure 4. Functional-structural model 
As FSMo also allows modelling the worker with the same elements, it provides a global and uniform view of the different energy flows within a man/machine system.

Based on this model, we proposed a method for identifying hazards throughout the design process: we have given it the acronym EZID for "Energy analysis for systematic haZard Identification during Design".

3. The EZID method

3.1. Description

As mentioned in section 1, the aim of this work is to help the designer to identify the hazards defined in the NF EN ISO 12100 standard [4], namely mechanical, electrical, thermal, vibration, noise, radiation, material/substance and ergonomic (limited to physical load in this article). There are also hazards associated with the environment in which the machine is used and the combination of hazard groups, though these are based on the previous eight groups.

The different elements that compose the method are presented (model, data and processes) for the designer that will use it. The method is based on FSMo to which we added reference data and processes to identify hazards (cf. Fig. 5). Note that the sole objective of this method is to identify potential hazards without covering the risk estimation/evaluation steps of the risk analysis that are already covered by numerous methods, as indicated above.

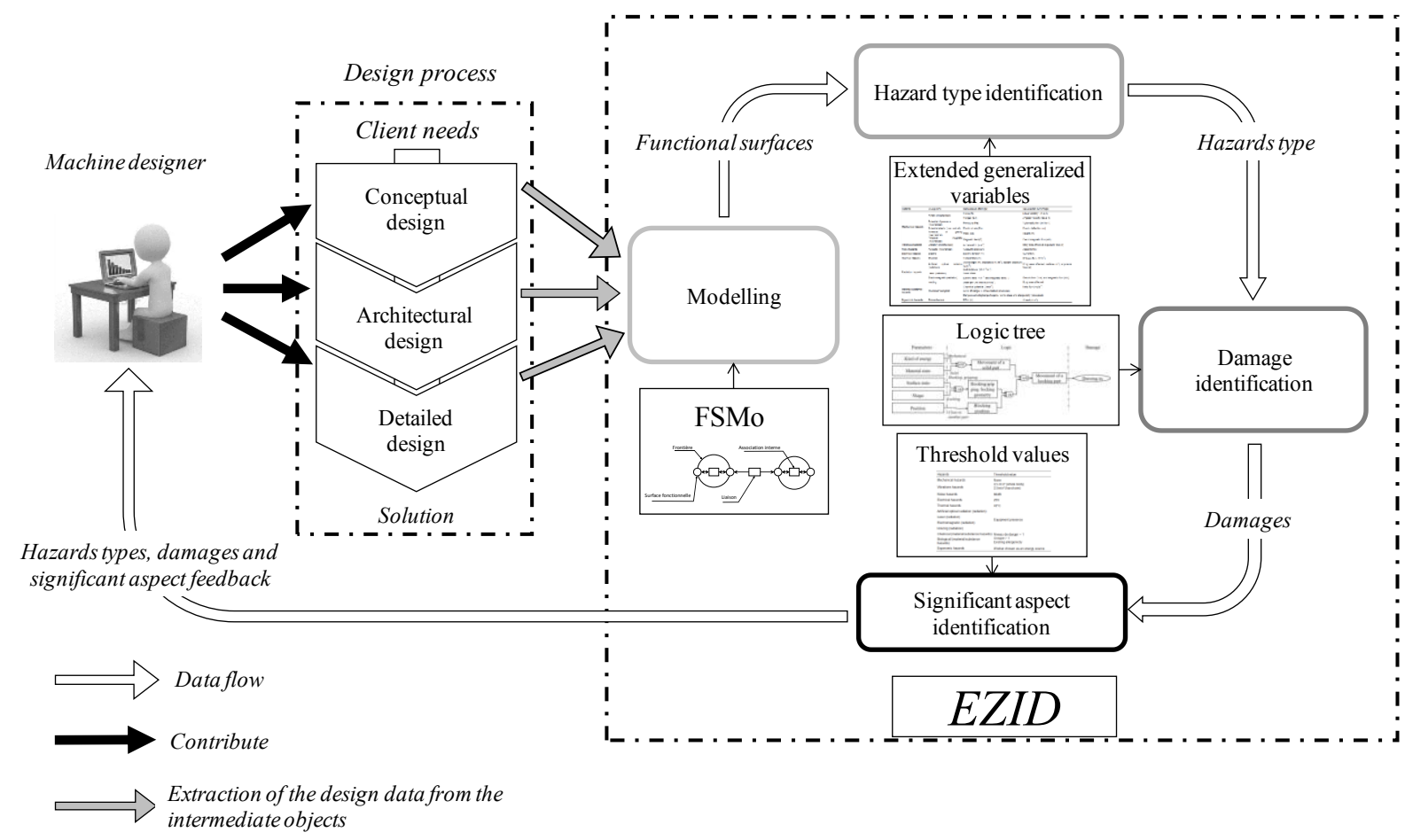

Figure 5. Global view of the EZID method

\subsubsection{Step 1: Modelling the machine being designed}

In the FSMo, functional surfaces are crossed by one energy flow and designate the interfaces through which a component has links to the other system elements, including the workers. Then, the identification of relevant hazards (identified as being present at, or associated with, the machine) linked to these energy flows becomes systematic by identifying all the functional surfaces.

These energies can be parts of the machine (e.g., electric motor, pneumatic cylinder, heating resistor), or generated by the worker (manual tasks) or also due to potential energies (e.g., gravity). These energies could also be wanted (specified by the designer) or unwanted (e.g., thermal energy related to friction, noise or vibrations generated by the movement of mechanical parts, mechanical energy (impact) linked to an unwanted movement of the operator) and occur during every step of the machine lifecycle. 
Consequently, two functional surfaces can be systematically defined for each component. The first one is linked to the potential energy due its mass: a mechanical hazard due to loss of stability (falling or tilting). The second corresponds to the energy necessarily provided by the operator to handle this component during the assembly or dismantling phase or also due to unintended contact and the risk of injury from sharp edges, for example.

To be used from the earliest design steps, it is necessary to explain how the FSMo should be modelled. At the beginning of the design process, the only available intermediate object is the client needs defined in the specifications document. In it, the client details at least the machine interactors (ex.: raw materials, trash, workers, energy sources, etc.), their exchanges (ex.: actions, energy flows, data exchange, etc.), and also some limitations for the machine characteristics (ex.: volume, mass, dimensions, etc.). Based on these data, the FSMo can represent the machine as a whole with a unique frontier since no information detail its components. In addition of this machine frontier, it is possible to represent all the interactors with separated frontiers and their exchanges with the machine and the other interactors. Based on the other intermediate objects (ex.: structural and kinematic architectures, CAD models, etc.) generated during the following steps of the design process, the user of EZID will be able to detail the component of the machine, if needed until its elementary parts. In consequence, the FSMo will evolve to details the previous machine frontier into multiples ones that will represent each component/part of the machine with their functional surfaces.

Then, after the functional surfaces of the FSMo have been identified, their parameters are analysed by other steps of EZID using reference parameters and different levels of processing in order to specify:

- $\quad$ the types of hazard (mechanical, electrical, chemical, ergonomic, etc.);

- $\quad$ the nature of damage: for example, crushing, cutting, severing, dragging for mechanical hazards;

- the hazards which may be considered significant (a hazard identified as relevant and which requires specific action by the designer to eliminate or reduce the risk according to the risk assessment), that is to say those which are sure to require specific actions from the designer.

To perform an exhaustive hazard identification, it is necessary to build an FSMo of the machine for each energy architecture representing the different working situations and/or lifecycle steps.

\subsubsection{Step 2: Hazard type identification}

This first level of processing allows associating the energy parameters of a functional surface to a type of hazard. This association is supported by the generalized variables of the Bond Graph model [37].

By using the concept of generalized variables, it is possible to split energy parameters into two categories: generalized effort (ge) and generalized currents ( $\mathrm{gc}$ ). They design the energy source and the energy flow, respectively. By extension, generalized power (gp) can be defined through the following relation: $g p=f(g e, g c)$. Table 1 contains the variables provided in the Bond graph theory.

Table 1: Generalized variables [38]

\begin{tabular}{|c|c|c|}
\hline Type of energy & Generalized effort (ge) & Generalized current (gc) \\
\hline \multirow{2}{*}{ Kinetic (mechanical) } & Force $(\mathrm{N})$ & Linear velocity (m.s-1) \\
\hline & Torque (N.m) & Angular velocity (rad.s-1) \\
\hline Pressure potential (mechanical) & Pressure $(\mathrm{Pa})$ & Volumetric flow $\left(\mathrm{m}^{\wedge} 3 . \mathrm{s}-1\right)$ \\
\hline Acoustic (mechanical) & Accoustic pressure & Acoustic flow \\
\hline Electric & Electric tension $(\mathrm{V})$ & Current (A) \\
\hline Thermal & Temperature $(\mathrm{K})$ & Entropic flow (W.K.-1) \\
\hline Electromagnetic (radiation) & Electric field $\left(\mathrm{V} . \mathrm{m}^{-1}\right)$ and magnetic field $(\mathrm{T})$ & Electric flow $(\mathrm{V} \cdot \mathrm{m})$ and magnetic flow $(\mathrm{Wb})$ \\
\hline Chemical & Chemical potential $\left(\mathrm{J} \cdot \mathrm{mol}^{-1}\right)$ & Mole flow $\left(\mathrm{mol} . \mathrm{s}^{-1}\right)$ \\
\hline
\end{tabular}

For some hazard types, the relationship with these generalized variables is obvious (e.g., mechanical energy/ mechanical hazard, electrical energy/electrical hazard).

For others, the generalized variables found in the literature are not those usually used by designers. For example, this is the case for chemical energy for which the generalized variables defined in the literature are chemical potential (ge) and molar flow (gc). These parameters are not usually used by or accessible to designers. In other 
cases we did not find generalized variables in the literature. For example, this was the case for vibratory, electromagnetic, ionizing, biochemical and biomechanical energies.

To overcome these difficulties, we decided to complete these generalized variables with parameters used to assess the severity of the corresponding hazard (for example, we distinguish the biomechanical energy provided voluntarily by the worker to the machine from the mechanical energy by using the generalised variables effort and speed, in order to identify ergonomic hazards). These extended generalized parameters are summarised in table 2 .

Table 2. Extended generalized variables [4, 39-45]

\begin{tabular}{|c|c|c|c|}
\hline Hazards & Type of energy & Generalized effort (ge) & Generalized current (gc) \\
\hline \multirow{6}{*}{ Mechanical hazards } & \multirow{2}{*}{ Kinetic (mechanical) } & Force $(\mathrm{N})$ & Linear velocity (m.s-1) \\
\hline & & Torque (N.m) & Angular velocity (rad.s-1) \\
\hline & $\begin{array}{l}\text { Potential of pressure } \\
\text { (mechanical) }\end{array}$ & Pressure $(\mathrm{Pa})$ & Volumetric flow (m^3.s-1) \\
\hline & Potential elastic (mechanical) & Elastic strain $(\mathrm{Pa})$ & Elastic deflection (m) \\
\hline & $\begin{array}{l}\text { Potential of } \quad \text { gravity } \\
\text { (mechanical) }\end{array}$ & Mass (kg) & Height (m) \\
\hline & Potential magnetic (mechanical) & Magnetic field (T) & Electromagnetic flow (Wb) \\
\hline Vibration hazards & Vibratory (mechanical) & Acceleration $\left(\mathrm{m} . \mathrm{s}^{-2}\right)$ & Body area affected, exposure time (s) \\
\hline Noise hazards & Acoustic (mechanical) & Acoustic pressure (dB) & Acoustic flow (m3/s) \\
\hline Electrical hazards & Electric & Electric tension (V) & Current (A) \\
\hline Thermal hazards & Thermal & Temperature $(\mathrm{K})$ & Entropic flow (W.K $\left.{ }^{-1}\right)$ \\
\hline \multirow{4}{*}{ Radiation hazards } & $\begin{array}{l}\text { Artificial } \\
\text { (radiation) }\end{array}$ & $\begin{array}{l}\text { Wavelength }(\mathrm{m}) \text {, irradiance }\left(\mathrm{W} \cdot \mathrm{m}^{-2}\right) \text {, } \\
\text { radiant } \quad \text { exposure } \\
\text { and radiance }\left(\mathrm{W} \cdot \mathrm{m}^{-2}\right) \\
\left.\text { - } \cdot \mathrm{sr}^{-1}\right)\end{array}$ & $\begin{array}{l}\text { Body area affected, surface }\left(\mathrm{m}^{2}\right) \text {, } \\
\text { exposure time }(\mathrm{s})\end{array}$ \\
\hline & Laser (radiation) & \multicolumn{2}{|l|}{ Laser class } \\
\hline & Electromagnetic (radiation) & $\begin{array}{l}\text { Electric field }\left(\mathrm{V} . \mathrm{m}^{-1}\right) \text { and magnetic } \\
\text { field }(\mathrm{T})\end{array}$ & $\begin{array}{l}\text { Electric flow }(\mathrm{V} \cdot \mathrm{m}) \text { and magnetic } \\
\text { flow }(\mathrm{Wb})\end{array}$ \\
\hline & Ionizing & Dose-per-unit intake $\left(\mathrm{Sv}_{\mathrm{Bq}} \mathrm{Bq}^{-1}\right)$ & Body area affected \\
\hline \multirow{3}{*}{$\begin{array}{l}\text { Material/substance } \\
\text { hazards }\end{array}$} & \multirow{3}{*}{ Chemical/biological } & Chemical potential $\left(\mathrm{J} \cdot \mathrm{mol}^{-1}\right)$ & Mole flow (mol.s $\left.{ }^{-1}\right)$ \\
\hline & & \multicolumn{2}{|l|}{ Level of danger + concentration (chemical) } \\
\hline & & \multicolumn{2}{|c|}{$\begin{array}{l}\text { Dangerous biological pathogens, class of toxicity and allergenicity } \\
\text { (biological) }\end{array}$} \\
\hline Ergonomic hazards & Biomechanical & Effort (N) & Speed $\left(\mathrm{m} \cdot \mathrm{s}^{-1}\right)$ \\
\hline
\end{tabular}

For some risks, hazard identification is based on the detection of technical solutions. For example, standard ISO 11688 [46] identifies pressure pulses, turbulences, impacts, etc. as noise hazard sources. It is therefore necessary to include this kind of element in the reference data. Also, during the design process, a designer can also specify energy source solutions without specifying the associated parameters: for example, an electrical motor is linked to a mechanical energy and to an electrical energy. Table 3 contains examples of technological solutions that provide energies and their corresponding hazards.

Table 3. Energy source solutions and their associated potential hazards

\begin{tabular}{ll}
\hline Examples of generic technical solutions & Potential hazards associated \\
\hline & Mechanical (output shaft) \\
& Electrical (power supply) \\
Electrical Motor & Vibration (structure fixing) \\
& Acoustic (friction between parts) \\
Electrical resistance or oven & Thermal \\
& Electrical (power supply) \\
& Thermal
\end{tabular}




\begin{tabular}{ll} 
& Mechanical \\
Pneumatic actuators & Noise (compressed air exhaust) \\
& Mechanical (potential energy due to pressure) \\
Ventilation or pneumatic transport system & Noise (airborne sound) \\
Gears & Mechanical \\
& Noise (solid-borne sound) \\
Vibratory Bowl or rail Feeder & Vibration \\
& Noise (solid-borne sound) \\
Hydraulic system & Noise (fluid-borne sound - cavitation) \\
& Mechanical (potential energy due to pressure) \\
Laser & Radiation (optical) \\
High frequency press & Thermal \\
X-ray electric generator & Radiation (electromagnetic) \\
Manual task & Radiation (ionizing) \\
\hline & Ergonomics \\
\hline
\end{tabular}

To conclude this step, by analysing the FSMo, the designer can identify all the relevant hazards present in the machine they designed, by identifying the functional surfaces and comparing the energy parameters (or technical solutions) with the reference data.

However, this identification of relevant hazards is not enough. Indeed, the designer needs to know about the significant hazards, that is to say, the hazards they must prevent. This additional identification requires clarifying the nature of the risk in order to check whether or not it comprises legal threshold values. If there are none, then the relevant hazard may indeed be qualified as significant. If there is one, it must be compared to the parameters characterizing the functional surface (or a combination of them) to determine this classification. This is presented in the following section.

\subsubsection{Step 3: Identification of damage and significant hazards}

It is first necessary to identify the damage linked to a hazard. Damage describes the consequences of a hazard for the worker. Of course, a type of hazard can injure a worker in different ways. For example, for the same mechanical energy, an element can lead to a risk of shock or cutting, depending on its shape (blunt or sharp edge).

To identify this damage, this process uses the energy parameters simultaneously with the other design parameters defined and which characterize functional surfaces. These other design parameters are called complementary parameters later in this paper.

We identified three main families of complementary parameters:

- Position parameters: they localize elements in the machine and include the position of the static elements, their accessibility and the trajectory of dynamic elements;

- Geometric parameters: they describe dimensions, shapes, surface states, etc.;

- Intrinsic parameters: they represent the specific characteristics of the elements such as their material properties and the features of the technological solutions.

By using the root-cause analysis [47] for each type of damage related to a given hazard, it is possible to define the complementary parameters of the corresponding energy parameters. The results are trees which defined logical rules of association that allowed the user of EZID to identify damages directly from the existence of selected design parameters (cf. Fig. 6). At present, the combinations suggested use only generic design parameters and "AND" and "OR" logical gates. This way, they can be used on any kind of machinery, confirming the generic aspect of the approach.

Thus, when a functional surface is created and its energy type is defined, the designer must check a list of the complementary parameters linked to this type of energy to identify the damage. As the project progresses, these 
complementary parameters may or may not be filled-in by the designer. As soon as a combination of these parameters is detected, the information of the potential damage is given to the designer. They can then choose or adapt a preventive solution for the specific damage.

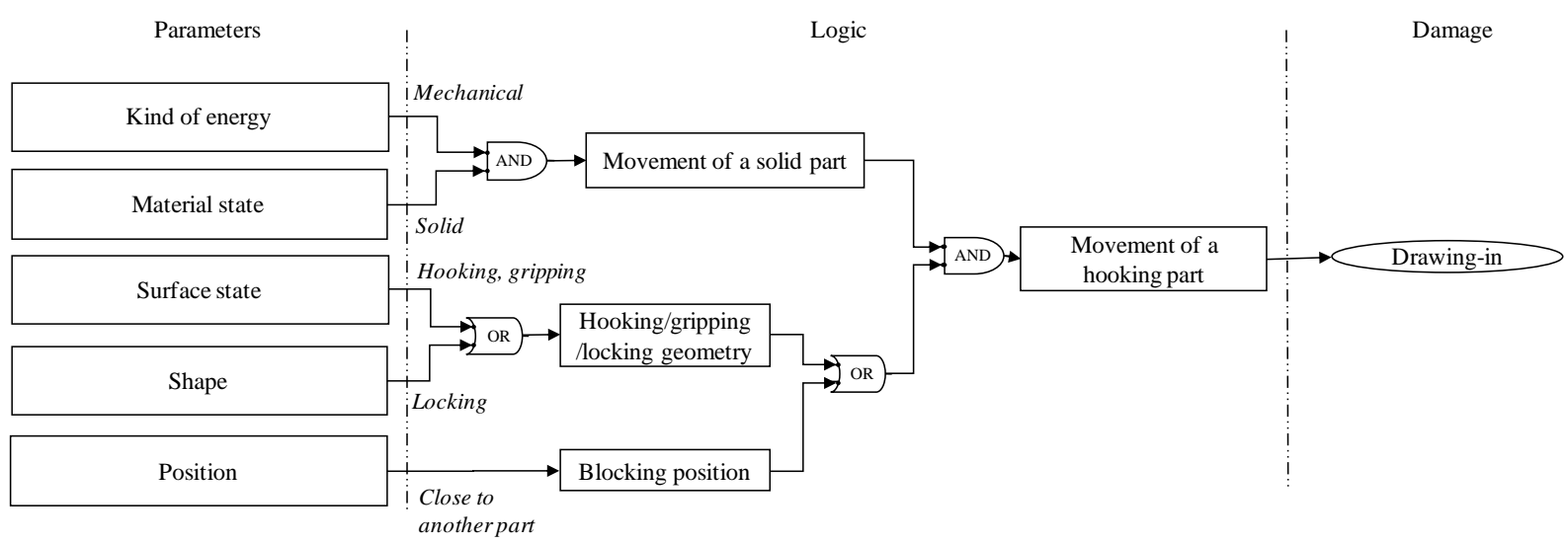

Figure 6. Examples of logical rules (trees) to create drawing-in damage

After this step, it is mandatory to check whether or not legal threshold values exist for the hazards or damage identified.

Some hazards or damage have threshold values to distinguish harmful energies from harmless ones. These values exist in the directives or safety standards and are recorded in the reference data of EZID (e.g., maximum handling weight is defined in [43], contact temperature in [42], etc.)

If the energy parameter value of a functional surface exceeds the threshold value, the hazard is considered significant. This is also the case if no threshold value exists. Then the designer must eliminate or reduce this hazard by modifying their project, as described in the next section.

If the energy parameter value is below the threshold, the hazard is confirmed as relevant. No specific action from the designer is required.

In the case where there is not enough data to perform this classification, the hazard is considered as "relevantunknown". Therefore, it is relevant but it can become significant depending on future design decisions.

The end of the EZID method occurs when feedback is supplied to the designer on the number and the source of hazards (functional surfaces), their types, their damage and which of them must be considered as significant. Therefore, the designer is alerted of the presence of these hazards as far upstream in the process as possible and throughout the remaining steps. Then they must estimate and evaluate the risks by using the different methods found in the literature. Finally, they must choose preventive measures according to the risk evaluation.

\subsubsection{The designer's actions}

According to the risk reduction process, the designer has two different possibilities: eliminate or reduce the risk by implementing inherently safe design measures or using guards or protective devices.

In the first case, this translates in the FSMo by the removal of the functional surface (corresponding to the hazard eliminated) or by the modification of the level of energy under the threshold level.

In the second case, the designer can specify "insulating links" to eliminate the transfer of energy between the targeted functional surface and the worker. If these "insulated links" are "energized" (mobile guards or laser system for example), the designer must integrate them in the FSMo in order to verify that they do not introduce new significant hazards.

When the operator is a source of energy (manual task), we create a new type of link that we call "adapted conductive link" (cf. Fig. 7). Of course, in order to prevent hazards generated by neglecting ergonomic principles, it is necessary to adapt the level of effort required for the operator according to human performance standards [48]. 
By conducting all these steps in a systematic process, the designer can identify every hazard in the machine selected at any moment of the design process. By using EZID, they can receive information on the kind of hazard, whether significant or not,
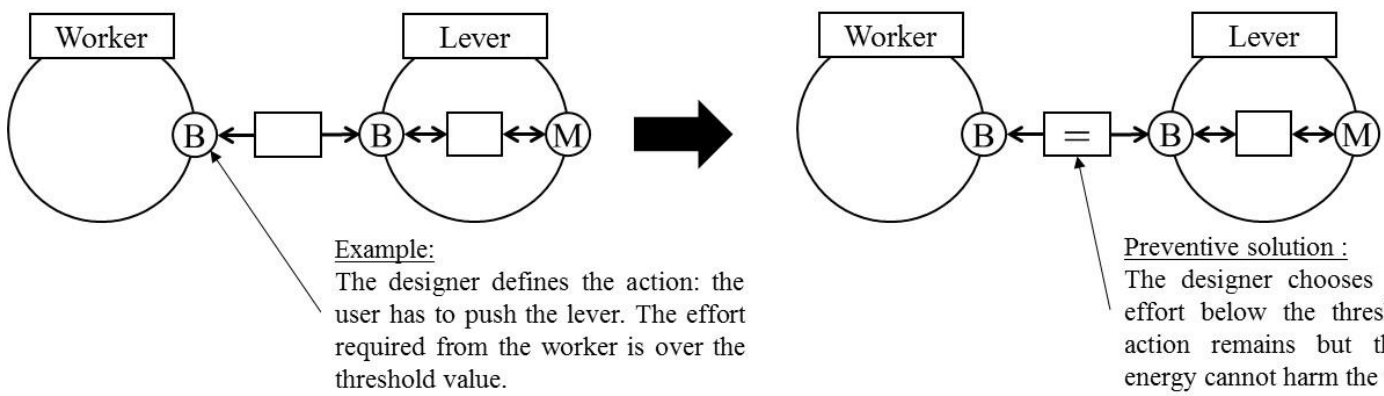

The designer chooses a lever with an effort below the threshold value. The action remains but the exchange of energy cannot harm the worker.

Figure 7. Transformation of a conductive link into an adapted conductive link

To verify its usability, EZID was applied to an industrial case. The next section presents the details of the experiment and the results obtained.

\section{Industrial experiment}

4.1. Industrial case

In order to check the relevance of EZID, it was applied a posteriori to the design project of an industrial supply line (cf. Fig. 8). This work was carried out by a design office dedicated to manufacturing machine design (Lormac Automation). The aim of this equipment to be incorporated in a production line is to transfer and control products. The operators have to place the product on the conveyor belt. The machine is composed of conveyors, actuators, a robotic arm and a vision system (camera + controlled light) for product control.

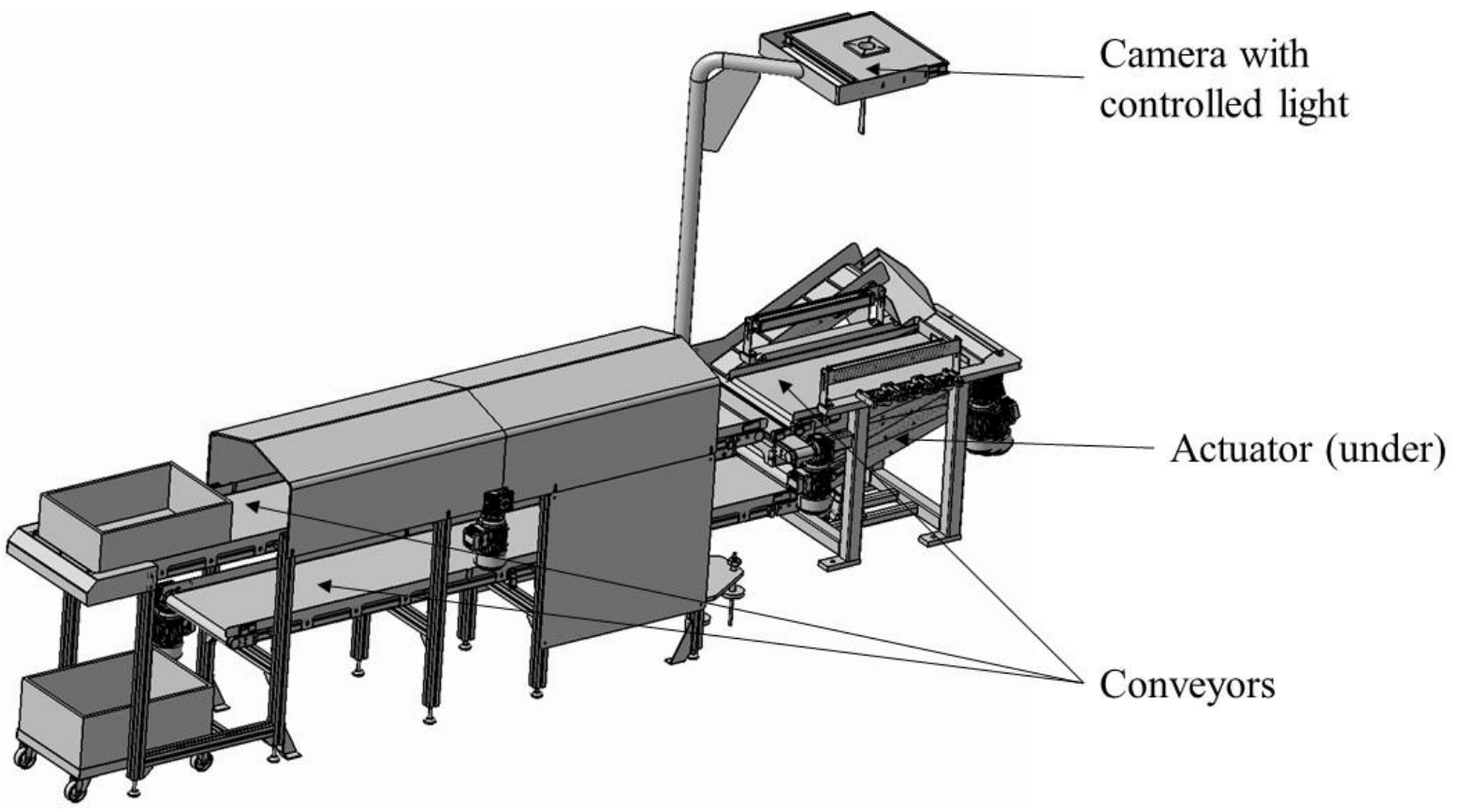

Figure 8. 3D CAD model of the supply line

We obtained from the designer all the intermediary objects generated or used during this project (requirement specifications, 3D CAD models, monitoring reports, subsystem datasheets). In order to apply EZID under the same conditions as if it had been applied during the design of the system, the first task consisted in positioning them chronologically in the conceptual, architectural and detailed design phases. Then the EZID method was applied manually by using the design data available at each moment. It was necessary to select the lifecycle step and the working situation since they directly influenced the energy architecture. 
For the sake of readability, all FSMo are represented in a simplified way. The letter in the main functional surfaces indicates the kind of energy (B: biomechanical energy, M: mechanical energy, P: potential energy of gravity, E: electrical energy, R: radiative energy). Also, two empty functional surfaces appear on every frontier (except for the worker) to represent the mechanical energies linked to their shapes (Ms) and masses (Mm), as explained in section 3.1.1.

\subsection{EZID application during the conceptual design stage} 4.2.1. Functional Structural modelling

The documents attributed to this phase specified the functional requirements from the customer in particular, the products concerned by the supply line and the main input energy capabilities (230-400 V / 50-60 Hz). The general operating principles were also described.

The products are packaged in two ways: loose in bags or boxes and organized in boxes. When the parts are loose, the bags or boxes must be opened manually by the operator and the parts placed loose on a conveyor. For the organized boxed products, the operator simply needs to manually open the box and put it on the conveyor. The non-conforming parts and the empty boxes are automatically directed towards the operator to be removed manually.

For the FSMo, the supply line is considered as a whole in interaction with the external elements: products, electric source, and the worker (cf. Fig. 9).

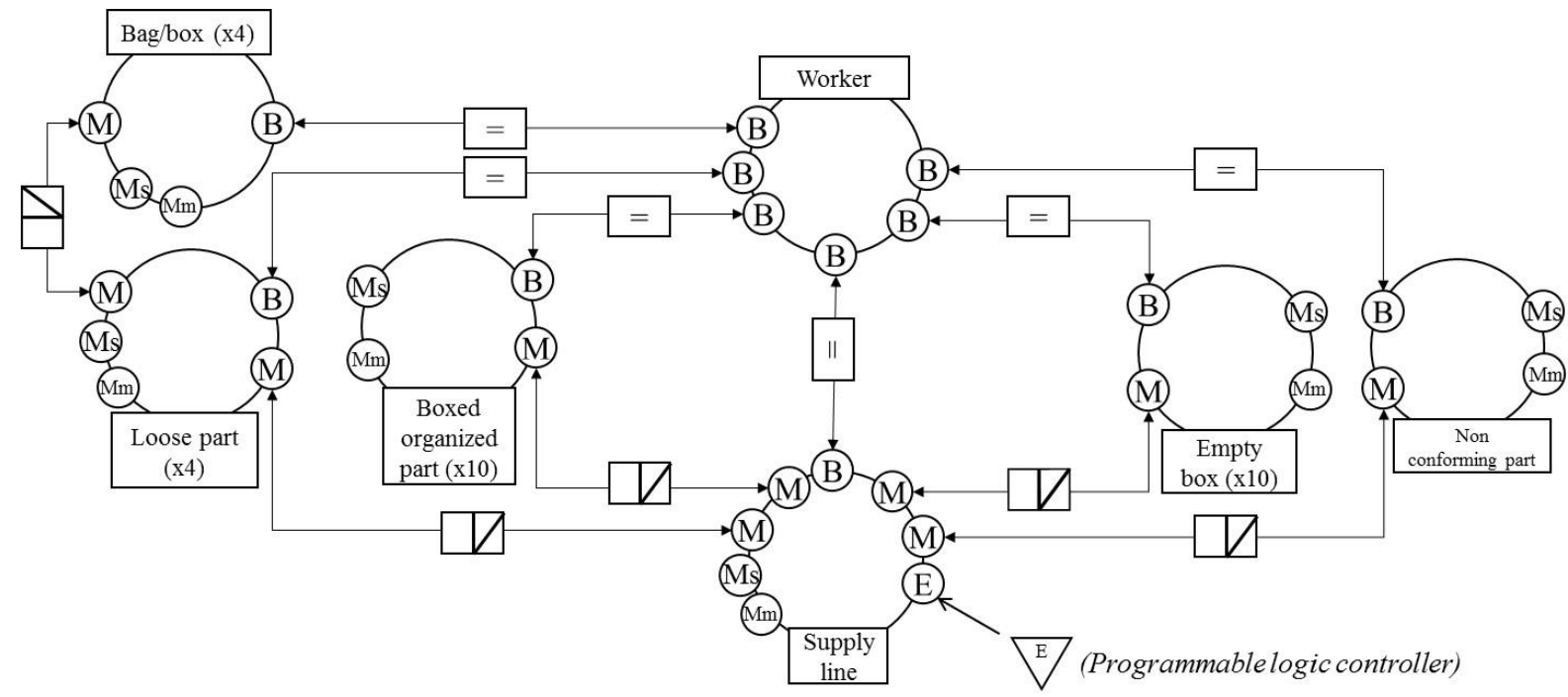

Figure 9. FSMo of the supply line for the conceptual design stage (for the usage lifecycle step)

\subsubsection{Hazard type identification}

Hazards are identified by the nature of the energies of the functional surfaces present in the FSMo. Although the parts and boxes do not physically belong to the machine and the designer does not design them, they are included in the machinery operation process. Therefore, all their functional surfaces must be analysed according to the EZID method.

There are 124 functional surfaces in this FSMo and thus 124 potential relevant hazards. The hazards identified are mainly related to the mechanical energy linked to the parts' shapes, their mass and their interactions with the machinery and/or the worker. Moreover, since it is specified that the main energy source of the system is electrical and that the supply of the parts is manual, electric source of the machine and the worker's actions also appear in the FSMo. Consequently, it is possible at this design stage, only with the data contained in the specifications document, to identify mechanical, electric and ergonomic hazards (cf. table 4).

\subsubsection{Identification of damage and significant hazards}

Since there are mechanical hazards, it is possible to identify some of the damage they generate. 
Only the parts and packages are well-known at this point and they all have blunt geometries. Therefore, using a logic tree similar to that illustrated in figure 5, only impacts and crushing damage are possible due to the unwanted energy provided by the worker and the falling of these items to the ground, respectively. Thus, for the 93 mechanical hazards identified, all of them can generate impacts and the 29 linked to weight can also cause crushing damage. Since mechanical hazards do not have threshold values, they are all automatically considered significant.

Regarding the ergonomic hazards, although the mass of the packs is less than $25 \mathrm{~kg}$, it is not yet possible to define the posture of the operator or the frequency of actions. Thus they must be considered as unknown at this point. The electric hazards due to the electric energy flow linked to the system $(230 \mathrm{~V}-400 \mathrm{~V} / 50-60 \mathrm{~Hz}) \mathrm{must}$ be considered as significant since the values are over the $25 \mathrm{~V}$ threshold [49].

Table 4. Results of the hazard identification during the conceptual design stage (for the usage lifecycle step)

\begin{tabular}{ccccc}
\hline Hazards & Relevant & Unknown & Significant & Damages \\
\hline Mechanical & 0 & 0 & 93 & Impact, crushing \\
Electrical & 0 & 0 & 1 & $/$ \\
Ergonomic & 0 & 30 & 0 & $/$ \\
Thermal & 0 & 0 & 0 & $/$ \\
Noise & 0 & 0 & 0 & $/$ \\
Vibration & 0 & 0 & 0 & $/$ \\
Radiation & 0 & 0 & 0 & $/$ \\
Chemical & 0 & 0 & 0 & $/$ \\
\hline
\end{tabular}

\subsubsection{Action by the designer}

It is mandatory for the designer to choose a preventive solution for every significant hazard, namely, mechanical and electrical hazards since they are significant. The ergonomic hazards are unknown at this stage but can become significant in the future. Thus it is not mandatory to select a preventive solution now but it is recommended to anticipate one.

The only preventive measure declared in the requirement specifications concerns conformity with ergonomic standards. This is represented on the FSMo by "adapted conductive links" between the worker and all the parts and boxes (cf. Fig. 9). However, none appear clearly for the mechanical and electrical ones. In fact, no effective preventive measures can be selected since the hazards identified are mainly linked to the external elements of the machinery. Furthermore, no structure is described by the designer, making it impossible to prevent any hazard linked to the machinery.

4.3. EZID application during the architectural design stage

$$
\text { 4.3.1. Model }
$$

To illustrate the following design phases, we focus on the supply of loose parts during use.

\subsubsection{Hazard type identification}

The number of functional surfaces describing the machine increases considerably in this design stage. This is because the machine is described as an assembly of subsystems and each of them has its own functional surfaces. Moreover, details on the dissipations of the internal links appear, creating new types of energy flows that do not contribute to the functioning of the machine. These are the reasons why there are 264 functional surfaces in this FSMo and thus 264 potential relevant hazards (cf. Fig. 10).

Mechanical hazard (M) is still the primary type of hazard in the machine, since the mechanical process is that detailed most in the intermediary elements. However, by detailing the machinery, the number of electric hazards (E) also increases because there is more than one subsystem requiring an electric source (conveyor, actuator, camera+light). The dissipation linked to the conveyors and the actuator generates thermal, noise and vibration hazards. A radiation hazard (R) appears because of the camera - controlled light system and the light received on 
the parts. The ergonomic hazards (B) are the same except that no interaction is required between the worker and the machine defined here.

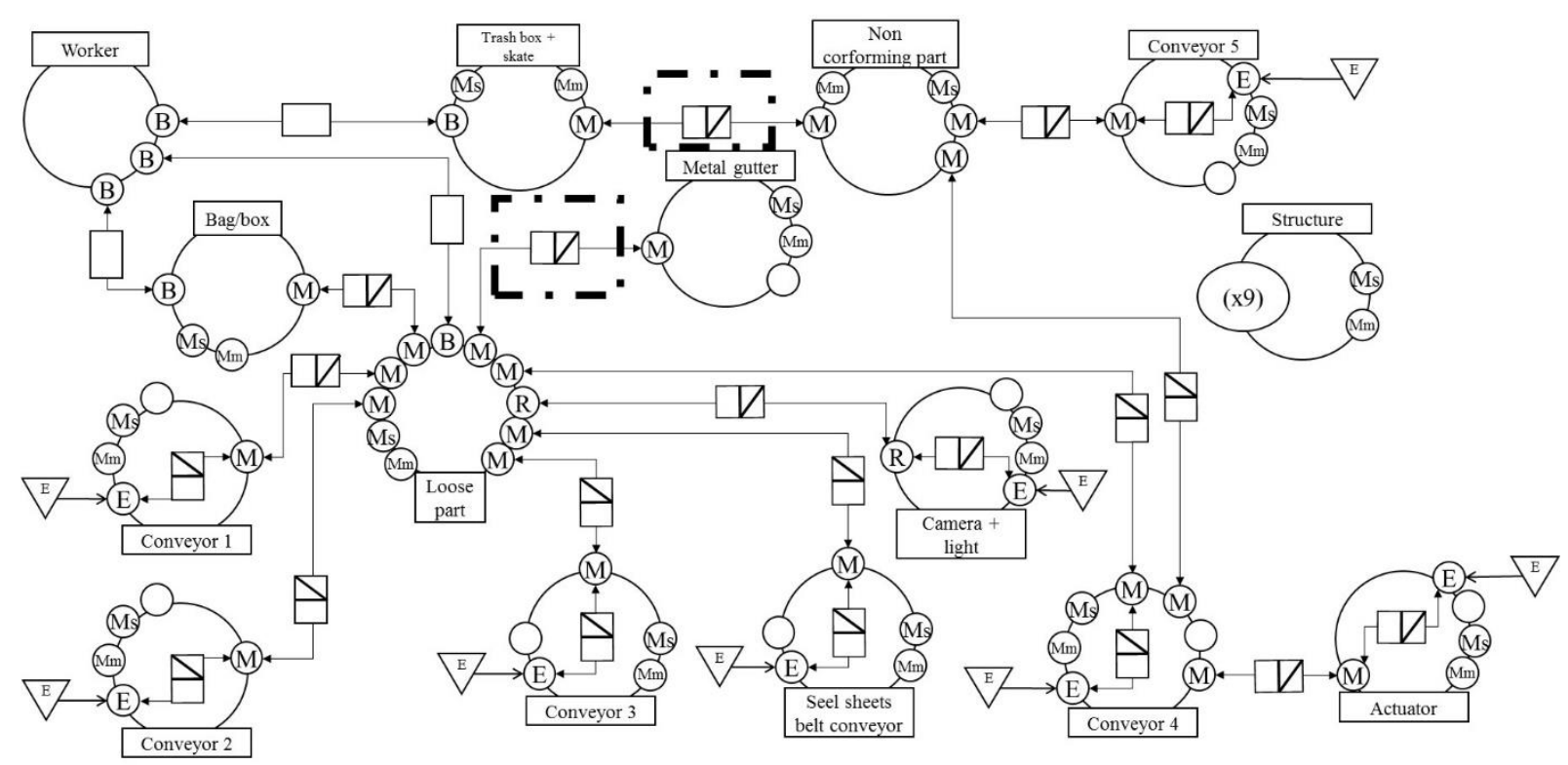

Figure 10. FSMo of the supply line for loose part management in the architectural design (to simplify the figure, the link with the structure (the blank functional surfaces) is not represented).

As said before, we focus on the reasons for the technical solutions for supplying loose parts. These parts circulate via a belt conveyor and a metal gutter. The reason here (impact between metallic parts) is recognized as generating noises [46] and recorded in the reference data (cf. table 2), Thus, EZID can identify the noise hazard linked to the technical solutions for supplying loose parts. Likewise for the technical solutions for recovering empty boxes or non-conforming parts: parts falling from conveyor 5 to the trash box. These two links are highlighted in figure 10.

Consequently, there are 200 mechanical, 8 electric, 29 ergonomic, 8 thermal, 7 vibration, 10 acoustic and 2 radiation hazards during the use of the machine with both loose and organized parts.

It is important to note that a link exists between the hazards identified at the conceptual and architectural design stages. For example, the two shapes and mass functional surfaces of the "supply lines" in fig. 9 are divided into as many surfaces on each sub-system (motor, conveyor, etc.) in fig. 10. Likewise for the main mechanical and electric energy flows. The ergonomic hazards remain the same.

\subsubsection{Identification of damage and significant hazards}

At this design stage, there are more data on the position and certain intrinsic parameters of the machine elements. For example, the conveyors have a gripping surface to move the parts. Thus, using logic trees similar to that illustrated in figure 5, the hazards linked to the kinetic energies created by the conveyors can generate drawingin damage. In addition, the area between consecutive conveyors can also create dragging damage when they have opposing movements directed toward the area. All the conveyors generate dragging and crushing damage as they can bustle the worker and they are positioned near other parts. Also, the areas under conveyors 4 and 5 are also subject to crushing damage. Table 5 summarises the results obtained by EZID at this stage.

Table 5. Results of hazard identification during the architectural design stage (for the usage lifecycle step)

\begin{tabular}{ccccc}
\hline Hazards & Relevant & Unknown & Significant & Damage \\
\hline Mechanical & 0 & 0 & 200 & Impact, crushing, drawing-in \\
Electrical & 0 & 0 & 8 & $/$ \\
Ergonomic & 0 & 29 & 0 & $/$ \\
Thermal & 0 & 8 & 0 & $/$ \\
Noise & 0 & 10 & 0 & $/$
\end{tabular}




\begin{tabular}{lllll} 
Vibration & 0 & 7 & 0 & 1 \\
Radiation & 2 & 0 & 0 & $/$ \\
Chemical & 0 & 0 & 0 & $/$ \\
\hline
\end{tabular}

Once again, all the mechanical hazards are significant. The noise and vibration hazard must be considered as unknown since the only data available are their existences. The irradiation of the light of the vision system is similar to natural white light. Therefore, the radiation hazard linked to it is relevant.

\subsubsection{Action by the designer}

For this stage too, it is mandatory for the designer to choose a preventive solution for the mechanical and electrical hazards since they are significant. The electrical, thermal, vibration, noise and ergonomic hazards are unknown at this stage but can become significant in the future. Thus, it is not mandatory to select a preventive solution now but it is recommended to anticipate one. The radiation hazards are only relevant so they do not need preventive measures.

The data obtained show that some mechanical parts protect the user from several mechanical dragging hazards. Also, the conveyors that interact with the user are in an ergonomic position. Since we are still at the architectural design stage, the electrical, thermal, vibration, noise and ergonomic hazards are not yet prevented. The data on the preventive measures chosen by the designer for these hazards belong to the detailed design stage.

At this stage, with EZID, it is possible to identify the noise hazards linked to the technical solutions for supplying loose parts and the recovery of empty boxes or non-conforming parts. In the real project, this hazard was identified only at the final reception and changes were requested by the end-user.

\subsection{Application of EZID during the detailed design stage 4.4.1. Model}

During the previous two design stages, we saw the evolution of the FSMo from a unique frontier (supply line) to multiple frontiers corresponding to subsystems. For the detailed design stage, this breakdown continues to the detailed parts of each subsystem. To illustrate this, we focus on the conveyor subsystem (cf. Fig. 11).

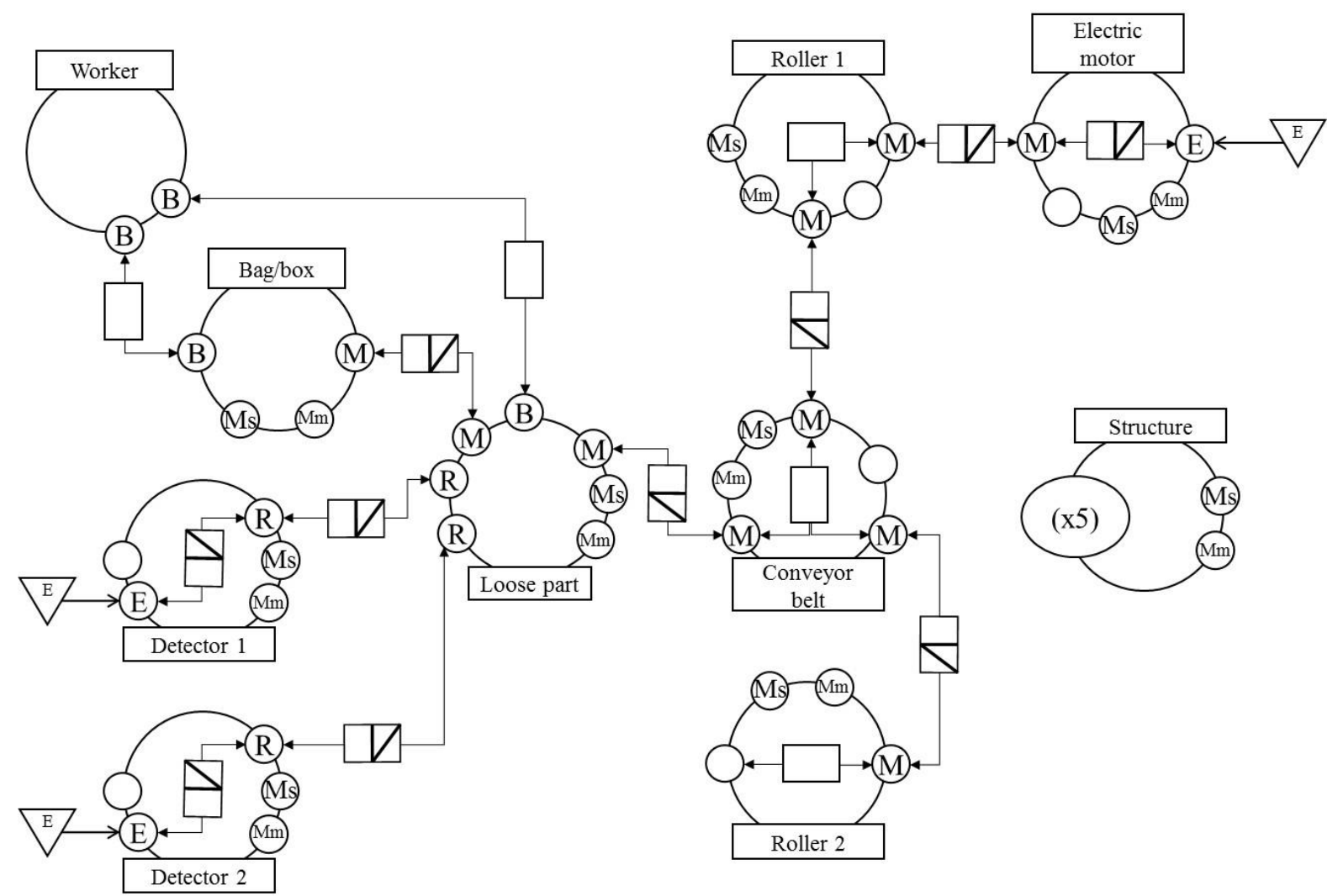


Fig. 11. FSMo of the loose part conveyor system in the detailed design

We do not develop every component in full since it is not necessary in certain cases. For example, if we take the electric motor of the conveyor, we can create an FSMo with its stator, rotor, gear and structure as represented in Figure 12. However, this is not common practice for machine designers. Generally, this is a standard purchased component and is certified for the whole subsystem.
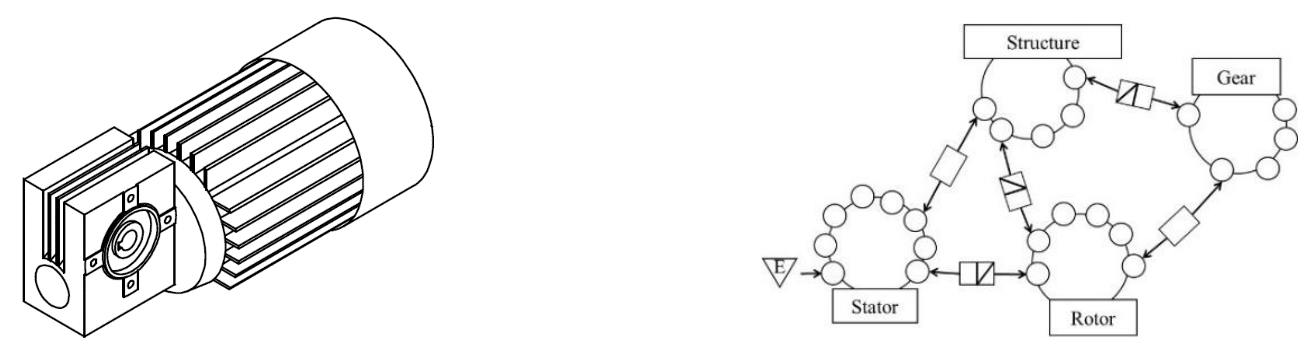

Fig. 12. Drawing of the conveyor electric motor (left) and its FSMo (right)

\subsubsection{Identification of hazard types}

Continuing from the results obtained with EZID for the architectural design stage, the number of functional surfaces increases since new frontiers appear. However, the type of energy and, logically, their related types of hazard remain the same since no changes have been made to the technical solutions. Rather than an increase in the number of mechanical hazards, there are more electric hazards because each conveyor contains 3 elements that use electricity as energy. Also, the two proximity detectors of the conveyor emit light radiation, thus adding radiation hazards to the results. There is no change in the number of hazards with the increase of conveyor details.

Consequently, 470 functional surfaces are detected for the usage lifecycle at the detailed design stage: 380 mechanical, 20 electric, 29 ergonomic, 8 thermal, 10 linked to noise, 7 linked to vibration and 16 linked to radiation (cf. table 6).

\subsubsection{Identification of damage and significant hazards}

Using logic tree processes similar to that illustrated in figure 5, it is possible to deduce that the electric motor can cause cutting hazards due to its shape (solid + sharp edge) and impact hazards (solid + blunt edge) due to the kinetic energy provided by the worker and dragging hazards (solid + surface state and/or proximity) linked to the kinetic energy provided by the electric motor. All the data on the relevant hazards are obtained by following the same pattern for the other machine parts.

Table 6 contains the damage and significant hazard identification results for the detailed design stage. Once again, the mechanical hazards are all considered significant. The electrical hazards linked to the motor/actuator/camera-light electric sources are still considered significant since they exceed the value of preventive extra-low voltage. Since no values are available on noises linked to parts falling on the metal gutter and the trash box-skate, their hazards must still be considered as unknown. Ergonomic hazards still require data on worker posture and the frequency of actions to be considered significant. Finally, by studying the characteristics of the energy sources, we note that thermal, vibration, remaining noises, radiation and electrical hazards linked to detectors have energy levels below the legal threshold levels. Consequently, they cannot be considered significant.

Table 6. Results of hazard identification during the detailed design stage (for the usage lifecycle)

\begin{tabular}{ccccc}
\hline Hazards & Relevant & Unknown & Significant & Damage \\
\hline Mechanical & 0 & 0 & 380 & Impact, crushing, drawing-in, \\
cutting \\
Electric & 12 & 0 & 8 & $/$ \\
Ergonomic & 0 & 29 & 0 & $/$ \\
Thermal & 8 & 0 & 0 & $/$ \\
Noise & 8 & 2 & 0 & $/$ \\
Vibration & 7 & 0 & 0 & $/$
\end{tabular}




\begin{tabular}{lcccc} 
Radiation & 16 & 0 & 0 & $/$ \\
Chemical & 0 & 0 & 0 & $/$ \\
\hline
\end{tabular}

\subsubsection{Action by the designer}

Preventive measures for mechanical hazards are selected at this stage. All the areas between consecutive conveyors are protected with a metal sheet to avoid dragging damage. All the elements are in theory well assembled with various solutions so there is no longer any risk caused by falling machine elements. The majority of the elements integrated in the supply line are commercial solutions and therefore satisfy safety standards. Consequently, mechanical hazards linked to the shape of elements are mainly prevented because the designers have incorporated chamfers and fillet radiuses to avoid angular shapes and points. The significant electric hazards are also prevented because of the safety measures employed by commercial solutions.

Not all the ergonomic and unknown noise hazards caused and the rest of the mechanical hazards linked to the movement of the elements such as the actuator are prevented according to the data of the last CAD model. Other intermediate objects must therefore be checked to ascertain whether the risk reduction process is complete.

\subsection{Results}

The designer relies on their experience to prevent most of the hazards during the different design stages. Most of the preventive measures integrated in the prototype concern the addition of safety guards, the correct fastening of the different elements and the transformation of angular shapes into blunt ones. Intrinsic prevention achieved through changing technologies or the organisation of parts was not considered.

For example, ergonomic hazards were not prevented in the stages observed. The designer did not modify the way the worker will interact with the machine. In addition, the initial solution of using the worker as a power supply for different actions was not reconsidered or adapted in the stages observed for any lifecycle step (e.g., use, assembly, setting, maintenance, disassembly).

Similarly, the noise hazard generated by parts falling on the metal gutter was prevented only when testing the prototype machine. The designer added a coating on the metallic gutter as a solution for absorbing the impact of the parts.

Finally, three electrical motors still impeded the worker's movements. Consequently, the worker could provide unwanted kinetic energy to the motor and injure themselves, especially during training or peak working times. Therefore it is necessary to increase the designer's awareness of all the hazards linked to every kind of energy.

Table 7 shows the final results of EZID applied to the prototype.

Table 7. Final results of EZID

\begin{tabular}{ccccc}
\hline Hazards & Relevant & Unknown & Significant & Damages \\
\hline Mechanical & 377 & 0 & 3 & Impact, crushing, drawing-in, \\
cutting \\
Electric & 20 & 0 & 0 & $/$ \\
Ergonomic & 0 & 29 & 0 & $/$ \\
Thermal & 8 & 0 & 0 & $/$ \\
Noise & 8 & 2 & 0 & $/$ \\
Vibration & 7 & 0 & 0 & $/$ \\
Radiation & 16 & 0 & 0 & $/$ \\
Chemical & 0 & 0 & 0 & $/$ \\
\hline
\end{tabular}

\section{Discussion and conclusion}

As stated in the "Machinery" directive, it is mandatory for designers to perform a risk analysis during the design process. However, although hazard identification is the central step of this analysis, there are no methods or tools dedicated to hazard identification and intended to help the designers of special machines. Therefore, they tend to focus on identifying the hazard closest to their field of experience and perform the whole risk analysis at the end 
of the design process. This leads to reducing the range of possible preventive solutions due to cost and schedule constraints.

The aim of the EZID method presented in this article is to solve hazard identification problems by proposing a structured approach based on intermediary objects and associated design parameters. Based on the hypothesis that hazards are linked to the presence of energy, it is possible to systematically identify hazards by analysing the energy properties of a machine and organizing them as relevant, unknown and significant. Performing an exhaustive hazard identification requires applying EZID to every step of any kind of machine lifecycle. EZID checks the four required characteristics defined in the introduction:

- $\quad$ generic because every kind of hazard can be identified, every machine can be studied and EZID is independent of the type of design process elements used by the designer;

- $\quad$ inductive because it uses design parameters (causes) to ascertain hazards (effects);

- dynamic and traceable because the FSMo evolves as a function of the design parameters defined and is not generated for each application;

- integrated and/or compatible with current design tools and methods because it is based on a design model (FSMo). EZID is currently adapted as an easy to use software application.

EZID method allows designers to complete the risk assessment process (estimation and evaluation steps) by supplying information on all significant hazards. Thus they are able to select the appropriate preventive solution.

The relevance of EZID for systematic hazards identification from the early stages of the design process is verified by its application on the data linked to the real design project of an assembly line supply subsystem. It validates the interest to analyse the energy flows to identify the different kinds of hazards. It also confirms that this identification can be done since the first steps of the design process, based on the intermediate objects generated (ex.: ergonomic hazards linked to the actions of the operator are identified based on the specifications document). The dynamic aspect is also verified with the persistence of untreated hazards during the entire design process and the identification of new hazards caused by the progressive definition of other components properties (ex.: position, material, etc.). The application of EZID on an industrial case finally validates its capability to identify hazards for other lifecycle steps of the machine. Therefore, EZID is capable of systematic hazard identification as it analyses all the energy configurations linked to the different lifecycle steps and operating mode of a given machine throughout the design process.

However, EZID have some limits for which we have perspectives:

- First, the threshold values currently used do not considered the exposition criteria. A first perspective is to add risk assessment and evaluation elements to EZID to propose a method that covers the entire risk appreciation process. In the same idea, we are currently working on the integration of life expectancy parameters in the functional surfaces, as it was done with the complementary parameters used in the logical rules, to identify hazards linked to the failure of the machine components.

- Also, EZID can only identify hazards directly linked to functional surfaces. A second perspective is to allow the method to identify hazard combinations that involve at least two hazards to create a different kind of hazard, such as electric hazard (spark) and chemical hazard (dust) that can create thermal hazard (explosion).

- Another limit is that the FSMo is only able to model energy flows. Since some other flows can contribute to the system safety, such as information flows, a third perspective is to add to the FSMo new elements, or to use the internal block diagram with modelling operators and rules, to extend the range of the hazard identification.

- $\quad$ Finally, the modelling step needs a lot of time to be done manually (several days in this paper case). The last perspective is to develop a prototype software application to drive the EZID method: construction of a functional-structural model, automatization of the different processes, capitalization of reference data, etc. This software will include different resources to allow its users to complete or adapt the reference data (e.g., generalized parameters, damage, logical rules) if necessary. Implanting EZID inside CAD softwares represents the final goal. Since CAD models can manage rules and circumstantial alerts based on the design data [50], it is not unrealistic to imagine a real time feedback to the designer about hazards based on the processing of EZID as it was done in [26]. 
To conclude, it is important to remember that the sole goal of the EZID method is to help designers identify hazards using a structured framework. It complements designers' tools and processes but does not replace project safety reviews or the other safety related designs we presented. It is solely a method for assisting designers in their work.

\section{Acknowledgments}

We would like to thank Lormac Automation, based in Tucquegnieux (France), for allowing us to observe the design process of a supply line, providing large amounts of data and answering our questions. This enabled us to validate the EZID method on a real project.

This work was performed in the framework of the joint INRS - ENSAM/ LCFC laboratory (safety design of work situations).

\section{References}

1. CNAMTS - Direction des risques professionnels, Tableaux de synthèse des statistiques nationales de la sinistralité 2014 de la branche AT-MP du régime général (Etude 2015-089). 2014.

2. Main, B.W. and McMurphy K.J., Safer by design: Reducing hazards through better designs. Professional Safety, 1998. 43(2): p. 29.

3. European Parliament and Council, Directive 2006/42/EC of the European Parliament and of the Council of 17 May 2006 on machinery, and amending Directive 95/16/EC (recast). 2006.

4. Standard, NF E09-001, NF EN ISO 12100 - Safety of machinery, General principles for design 2010, AFNOR

5. Insee, Caractéristiques comptables, financières et d'emploi des unités légales en 2013, Insee. 2015.

6. Fadier, E. and C. De la Garza, Safety design: Towards a new philosophy. Safety Science, 2006. 44(1): p. 55-73.

7. Boujut, J.-F. and Blanco, E., Intermediary objects as a means to foster co-operation in engineering design. Computer Supported Cooperative Work (CSCW), 2003. 12(2): p. 205-219.

8. Godot, X., et al., Methodology to develop a geometric modeling process according to collaborative constraints. International Journal on Interactive Design and Manufacturing (IJIDeM), 2014: p. 1-17.

9. Scaravetti, D., et al., Structuring of embodiment design problem based on the product lifecycle. International Journal of Product Development, 2005. 2(1): p. 47-70.

10. Schroer, S. and M. Modarres, An event classification schema for evaluating site risk in a multi-unit nuclear power plant probabilistic risk assessment. Reliability Engineering \& System Safety, 2013. 117(0): p. 40-51.

11. Kjellén, U., Safety in the design of offshore platforms: Integrated safety versus safety as an add-on characteristic. Safety Science, 2007. 45(1-2): p. 107-127.

12. Rusli, R., A.M. Shariff, and F.I. Khan, Evaluating hazard conflicts using inherently safer design concept. Safety Science, 2013. 53: p. 61-72.

13. Sadeghi, L., et al., Design for Human Safety in Manufacturing System: A Review of Applications of Design Theories and Methodologies (DTM) and Design Tools and Techniques (DTT). Journal of engineering design, 2016.

14. Hale, A.R. and Swuste P., Safety rules: procedural freedom or action constraint? Safety Science, 1998. 29(3): p. 163-177.

15. Rausand, M. and Bouwer Utne, I., Product safety - Principles and practices in a life cycle perspective. Safety Science, 2009. 47(7): p. 939-947.

16. Vink, P., Urlings, I.J.M. and van der Molen, H.F., A participatory ergonomics approach to redesign work of scaffolders. Safety Science, 1997. 26(1-2): p. 75-85.

17. Jouffroy, D., et al., An approach to integrate safety at the design stage of numerically controlled woodworking machines, in Integrated Design and Manufacturing in Mechanical Engineering'98. 1999, Springer. p. 643-650.

18. Hale, A., Kirwan, B. and Kjellén, U., Safe by design: where are we now? Safety Science, 2007. 45(12): p. 305-327.

19. Janssens, J., et al., A decision model to allocate protective safety barriers and mitigate domino effects. Reliability Engineering \& System Safety, 2015. 143: p. 44-52.

20. Vijayan, A., et al., Degradation of fluorescent high-visibility colors used in safety garments for the Australian railway industry. Journal of Safety Research, 2016. 56: p. 1-7.

21. Cocca, P., Marciano, F. and Alberti, M., Video surveillance systems to enhance occupational safety: A case study. Safety Science, 2016. 84: p. 140-148. 
22. Lamy, P. and Charpentier, P., ND 2305-214-09 Estimation des risques machines - Recensement des méthodes et subjectivités des paramètres de l'estimation. Hygiène et sécurité du travail, 2009. 214.

23. Hu, J., Zhang, L. and Liang, W., An adaptive online safety assessment method for mechanical system with pre-warning function. Safety Science, 2012. 50(3): p. 385-399.

24. Lyon, B.K., Popov, G. and Hanes, K., Improving Ergo IQ: A Practical Risk Assessment Model. Professional Safety, 2013. 58(12): p. 26-34.

25. Coulibaly, A., Houssin, R. and Mutel, B., Maintainability and safety indicators at design stage for mechanical products. Computers in Industry, 2008. 59(5): p. 438-449.

26. Shahrokhi, M. and Bernard, A., A framework to develop an analysis agent for evaluating human performance in manufacturing systems. CIRP Journal of Manufacturing Science and Technology, 2009. 2(1): p. 55-60.

27. Ghemraoui, R., Mathieu, L. and Tricot, N., Design method for systematic safety integration. CIRP Annals - Manufacturing Technology, 2009. 58(1): p. 161-164.

28. Hasan, R., et al., Integrating safety into the design process: elements and concepts relative to the working situation. Safety Science, 2003. 41(2-3): p. 155-179.

29. Haddon, W., Energy damage and the 10 countermeasures strategies. J Trauma, 1973. 13(4): p. 321-331.

30. Kjellén, U., Prevention of accidents through experience feedback. 2000: Taylor and Francis.

31. Paynter, H.M., Analysis and Design of Engineering Systems. 1961.

32. David, M. and Clement, M., Structured Analysis and Design Technique. 1987: McGraw-Hill.

33. Horrein, L., et al. Représentation-Simulation de Générateurs Thermoélectrique au travers de la Représentation Energétique Macroscopique. in Symposium de Génie Électrique 2014.

34. Mario, S., Der Einsatz von Sankey-Diagrammen im Stoffstrommanagement. Beitraege der Hochschule Pforzheim, 2006(124): p. 8.

35. SysML TM, O. SysML v1.4 Specification. 2015; Available from: http://www.omgsysml.org/.

36. Constant, D., Contribution à la spécification d'un modèle fonctionnel de produits pour la conception intégrée de systèmes mécaniques. Thèse 1996, Université de Grenoble 1.

37. Roucoules, L., et al., Une approche au juste nécessaire de l'intégration métier, en conception vers des solutions alternatives innovantes. Ingénierie de la conception et cycle de vie des produits. 2006: ed HERMES.

38. Borutzky, W., Bond graph methodology: development and analysis of multidisciplinary dynamic system models. 2009: Springer Science \& Business Media.

39. Standard, NF C13-200 - Installations électriques à haute tension. 2002.

40. Standard, NF EN ISO 5349 - Measurement and evaluation of human exposure to hand-transmitted vibration. 2002.

41. Standard, NF EN 50505:2006 - Basic Standard For The Evaluation Of Human Exposure To Electromagnetic Fields From Equipment For Resistance Welding And Allied Processes 2006.

42. Standard, NF X35-112, NF EN ISO 13732, Ergonomics of the thermal environment - Methods for the assessment of human responses to contact with surfaces 2008, AFNOR.

43. Standard, NF X35-106, NF EN 1005, Safety of machinery - Human physical performance. 2008, AFNOR.

44. Council, Council Directive 2013/59/EURATOM of 5 December 2013 laying down basic safety standards for protection against the dangers arising from exposure to ionising radiation, and repealing Directives 89/618/Euratom, 90/641/Euratom, 96/29/Euratom, 97/43/Euratom and 2003/122/Euratom. 2013.

45. Standard, NF C43-890-2008 photobiological safety of lamps and lamp systems. 2008.

46. Standard, NF S31-510, NF EN ISO 11688 du 2009-11-01 - Recommended practice for the design of low-noise machinery and equipment 2009.

47. Wilson, P.F., Dell, L.D. and Anderson, G.F., Root Cause Analysis: A Tool for Total Quality Management. 1993, Milwaukee, Wisconsin: ASQ Quality Press.

48. Standard, NF EN 1005 - Safety of machinery - Human physical performance. 2008, AFNOR.

49. Standard, NF EN 60204 - Safety of machinery - Electrical equipment of machines. 2009, AFNOR

50. González-Lluch, C., et al., A survey on 3D CAD model quality assurance and testing tools. ComputerAided Design, 2017. 83: p. 64-79. 